Article

\title{
Spatial Heterogeneity of Farmland Abandonment in the Sichuan Province, China
}

\author{
Youhan Wang ${ }^{1,2}$, Peihao Peng ${ }^{1, *}$, Qian $\mathrm{Li}^{3}$, Zhongsheng Chen ${ }^{2} \mathbb{C}$ and Wenbin Tang ${ }^{1}$ \\ 1 College of Earth Sciences, Chengdu University of Technology, Chengdu 610059, China; \\ youhanwang@cwnu.edu.cn (Y.W.); tangwenbin@stu.cdut.edu.cn (W.T.) \\ 2 School of Land and Resources, China West Normal University, Nanchong, Sichuan 637009, China; \\ chenzhs@cwnu.edu.cn \\ 3 Business School, China West Normal University, Nanchong, Sichuan 637009, China; liqian@cwnu.edu.cn \\ * Correspondence: pengpeihao@cdut.edu.cn; Tel.: +86-159-8232-8087
}

Received: 2 March 2020; Accepted: 14 April 2020; Published: 20 April 2020

\begin{abstract}
Urbanization and regional geomorphological and agricultural conditions have caused rural hollowing out and a large number of farms to be abandoned, which is a big obstacle to food security and rural industrial development. Sichuan Province is representative of national major grain producing areas and high-quality cultivated protected land in China. This paper reveals the spatial heterogeneity of farmland abandonment in the Sichuan Province. In total, 455 random sample plots were investigated to explore spatial heterogeneity of abandoned farmland in Sichuan Province. In each sample plot, farmland and abandoned farmland patches were mapped. The rate of paddy field abandonment (RPFA), the rate of non-irrigated farmland abandonment (RNFA), and the rate of farmland abandonment (RFA) were calculated as indicators of farmland abandonment. Our results reveal the spatial heterogeneity of abandoned farmland in Sichuan Province, and the clustering characteristics of spatial cold- and hot spots of the RFA. The findings from this study may have importance in rural infrastructure construction and the implementation of a rural revitalization strategy, as well as in making policies to curb abandonment of farmland. The spatial heterogeneity of farmland abandonment revealed in this study may contribute to sustaining food security and farmland protection in China.
\end{abstract}

Keywords: farmland abandonment; spatial heterogeneity; sample plots; RPFA; RNFA; RFA; Sichuan Province

\section{Introduction}

Since the second half of the twentieth century, farmland abandonment has occurred in many developed countries [1]. The reasons for this phenomenon include migration of agriculturalists [2,3] which has led to a reduction in the agricultural labor force [4-6], declining farmland use [7,8], low reward from agriculture [9,10], and prevailing policies on agriculture [11-13]. Rural hollowing, which has been accompanied by wide abandonment of farmland, has been evident in China since 2000. During 2014-2015, about $12.29 \%$ of cropland in Chinese mountainous areas was abandoned [14]. Farmland abandonment is more prevalent in hilly or mountainous areas in China; e.g., in southwestern regions, and less prevalent in eastern plains [15], where reward from agricultural industry is high. Of the 165 counties and cities with serious farmland abandonment in China, 23 counties are located in Sichuan Province [16]. A number of studies have investigated the spatial pattern of cropland abandonment in Poland [17], Europe [18,19], and China [16,20]. Mountainous areas, such as the Three Gorges Reservoir Area in southwestern China, are considered hot spots of farmland abandonment [14,21,22]. To date, there has been no study based on surveyed patches of abandoned farmland on a provincial scale, especially in Sichuan Province. 
Sichuan Province is a national grain-producing area that encompasses areas of high-quality protected farmland in China. In recent years, as farmers go out for work, the phenomenon of rural hollowing and farmland abandoning is more and more prominent. However, up to this date, there is still a lack of comprehensive survey on the farmland abandoning and its influencing factors in Sichuan Province. Wang (2017) applied low-resolution remote sensing data to extract information about abandoned farmland [23]. Shi (2016) extracted information on abandoned cropland by conducting a superposition analysis of a two-stage land use status database [3]. Researchers mapped the extent of abandoned farmland using MODIS NDVI time series satellite data [18,24]. However, these methods have limited reference value for research in Sichuan Province, due to its complex landforms and greatly fragmented farmland.

The objective of this article is to map the spatial heterogeneity of farmland abandonment in Sichuan Province. Mapping of abandoned farmland patches based on $1 \mathrm{~km}-\mathrm{by}-1 \mathrm{~km}$ plots and high-resolution images was conducted to collect data. In total, 501 sample plots were selected randomly for investigation. Then a statistical analysis was conducted to reveal the spatial heterogeneity of farmland abandonment in Sichuan Province using accurate spatial information of abandoned farmland patches.

The rate of paddy field abandonment (RPFA), the rate of non-irrigated farmland abandonment (RNFA), and the rate of farmland abandonment (RFA) are employed indicators to quantify farmland abandonment. RPFA is the ratio of abandoned paddy fields to the total area of paddy fields (including abandoned paddy fields and cultivated paddy fields) in a surveyed sample plot. RNFA means the proportion of non-irrigated abandoned farmland area to the total area of non-irrigated abandoned farmland (including abandoned non-irrigated farmland and cultivated non-irrigated farmland) in a surveyed sample plot. RFA denotes the proportion of abandoned farmland to the total area of abandoned farmland (including abandoned paddy fields, cultivated paddy fields, abandoned non-irrigated farmland and cultivated non-irrigated farmland) in a surveyed sample plot. Methods including the semi-variogram, and cold- and hot-spot analysis of RPFA, RNFA, and RFA are applied to explore the spatial heterogeneity of farmland abandonment in the Sichuan Province. We discuss the results in Section 4, and present key conclusions in Section 5. The study clarifies the spatial heterogeneity of farmland abandonment in rural Sichuan Province, and has important implications in terms of Chinese food security and farmland protection.

\section{Study Area, Data Collection, and Methods}

\subsection{Study Area}

Sichuan Province is located in southwestern China, stretching across the upper reaches of the Yangtze River between the latitudes of $26^{\circ} 03^{\prime}$ and $34^{\circ} 19^{\prime} \mathrm{N}$ and the longitudes of $97^{\circ} 21^{\prime}$ and $108^{\circ} 31^{\prime}$ $\mathrm{E}$ [25]. It covers an area of $486,000 \mathrm{~km}^{2}$, about $5 \%$ of China's terrestrial area [26,27]. Sichuan encompasses several major geomorphic units, including the Qinghai-Tibet Plateau, the Hengduan Mountains, the Yunnan-Kweichow Plateau, the Chengdu Plain, the Tsinling Mountains, and the Sichuan Basin. The topography is high in the west and low in the east, with an incline extending from the northwestern part of the province to the southeastern part [28]. It becomes increasingly complex and diverse from the west to the east, evidenced by varying landforms, crisscrossing rivers, and significant differences in elevation. The geomorphic types of Sichuan can be divided into Western Sichuan Alpine Plateau, South West Sichuan Mountain Area, Basin Periphery Mountain Area, West Basin Plain, and Hilly Area in Basin [29], as shown by Figure 1. The plateau and High Mountains are located in the western part of the Sichuan Province, which are at an elevation of over $4000 \mathrm{~m}$. The elevation of the West Basin Plain is about $500 \mathrm{~m}$. The eastern part mainly comprises the basin and hills with elevation of 250-1500 m. Sichuan Province has a subtropical monsoon climate, and is rich in water systems, diverse flora and fauna, and abundant resources [30]. There are 183 counties under its jurisdiction. At the end of 2018, the resident population of Sichuan Province was 83.41 million, with an urbanization rate of $52.29 \%$, 
and the gross domestic production of Sichuan Province was 4067.81 million CNY (586.58 million U.S. dollars). The per capita disposable income of its residents was 22,461 CNY (3238.88 U.S. dollars), and the total area of farmland was 6,725,935 ha [31].

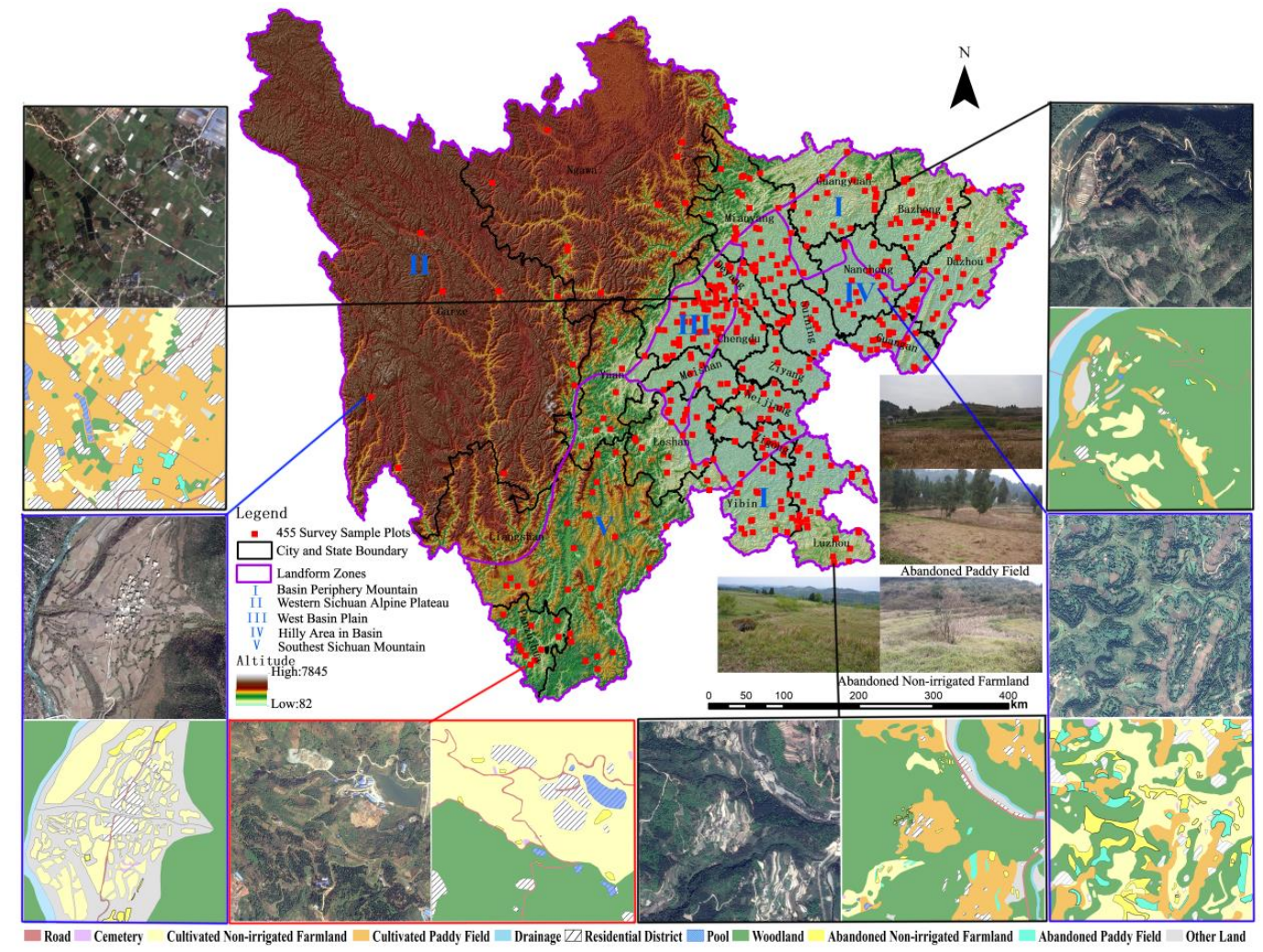

Figure 1. Distribution of surveyed sample plots in Sichuan Province, and the examples of sampled plots.

\subsection{Data Collection}

\subsubsection{Farmland Abandonment Patches Survey}

Farmland abandonment implies decreased utilization frequency of farmland [11]. It includes two types: actual abandonment and semi-abandonment. Actual abandonment of farmland is defined as total cessation of cultivation in any form. Farmland is considered to be semi-abandoned when it is not used for agricultural production, but where there are certain signs of it being cultivated or managed [32]. In this paper, patches of semi-abandoned farmland were investigated; actual abandoned farmland was excluded. The term abandoned farmland refers to land which was previously planted with vegetables and food crops but was abandoned at the time of the survey, especially farmland that had been abandoned for more than one year. Farmland was divided into two categories: abandoned farmland and cultivated farmland. There are two categories of abandoned farmland: abandoned non-irrigated farmland and abandoned paddy fields. Correspondingly, cultivated farmland was divided into two categories: cultivated non-irrigated farmland and cultivated paddy fields.

The survey was released to 867 undergraduate students majoring in geography and living in rural areas of Sichuan Province, who were chosen to map patches of abandoned farmland and cultivated farmland, and 501 students voluntarily participated in the survey. Therefore, the 501 sample plots were randomly selected. Firstly, they found their own residential district in Google Earth, and selected a $1 \mathrm{~km}$-by-1 km plot located near their own residential sites. The plots of images were download using BIGMAP tools from Google Earth (no offset data), and saved in the GeoTIFF format. The World Geodetic System 1984 (WGS84) was applied to achieve the projected transformation. Since the spatial range of each sample plot was $1 \mathrm{~km}^{2}$, the deformation caused by image projection was disregarded. Secondly, the image of each plot from Google Earth was printed on waterproof paper 
for the convenience of survey mapping. The survey of patches was conducted by 501 students in their hometowns during January and February in 2016, 2017, and 2018, and each student investigated a sample plot independently. According to the technical regulations of the Ministry of Land and Resources of the People's Republic of China (TD/T1014-2007), the 501 students drew boundaries of different land-use types in waterproof paper on the survey images. They focused on three categories of land-use types: (1) abandoned non-irrigated farmland and abandoned paddy fields, (2) cultivated non-irrigated farmland and cultivated paddy fields, and (3) land related to agricultural activities, including drainage, pools, cemeteries, roads, ditches, residential districts, woodland, and other land. The 501 sample plots were surveyed over the three years, 36 in 2016, 289 in 2017, and 176 in 2018. The survey maps were taken back, and we obtained 455 valid sample plots (Figure 1), with 46 sample plots excluded because the map contents did not reflect the actual situation, or the legend of the survey map was not clear, or the areas were located in an urban zone. The 455 sample plots were mainly concentrated in the West Basin Plain (73 plots), Hilly Area in Basin (148 plots), and Basin Periphery Mountain Area (141 plots), where the primary grain-producing areas in Sichuan Province are. Of the remaining sample plots, 52 sample plots were distributed in the South West Sichuan Mountain, and 41 sample plots were located in the Western Sichuan Alpine Plateau, which has limited land resources and sparse population [33].

\subsubsection{Database Construction}

The land-use database of 455 survey maps was constructed by ArcGIS 10.3. In total, 57,625 patches were identified, which encompassed 6016 abandoned non-irrigated farmland patches, 3881 abandoned paddy field patches, 9173 cultivated non-irrigated farmland patches, and 6105 cultivated paddy field patches. The land use of patches in sample plots is illustrated in Figure 1.

The digital elevation model (DEM, resolution $30 \mathrm{~m}$ ) of the sampled plots was sourced from ASTER GDEM V2 (Advanced Space-borne Thermal Emission and Reflection Radiometer Global Digital Elevation Model Version 2), and the data set was provided by Geospatial Data Cloud site, Computer Network Information Center, Chinese Academy of Sciences (http://www.gscloud.cn/).

\subsection{Quantification of Spatial Heterogeneity}

\subsubsection{Calculation of RPFA, RNFA, RFA}

RPFA, RNFA, and RFA were calculated using Formulas (1)-(3), respectively.

$$
\begin{aligned}
& \mathrm{RPFA}^{k}=\frac{\sum_{i=1}^{n} A_{(\mathrm{RPFA}) i}^{k}}{\sum_{i=1}^{n} A_{(\mathrm{RPFA}) i}^{k}+\sum_{i=1}^{n} a_{(\mathrm{RPFA}) i}^{k}} \\
& \mathrm{RNFA}^{k}=\frac{\sum_{i=1}^{n} A_{(\mathrm{RNFA}) i}^{k}}{\sum_{i=1}^{n} A_{(\mathrm{RNFA}) i}^{k}+\sum_{i=1}^{n} a_{(\mathrm{RNFA}) i}^{k}} \\
& \mathrm{RFA}^{k}= \sum_{i=1}^{n} A_{(\mathrm{RPFA}) i}^{k}+\sum_{i=1}^{n} A_{(\mathrm{RNFA}) i}^{k} \\
& S_{\mathrm{RPFA}}^{k}+S_{\mathrm{RNFA}}^{k} \\
& S_{\mathrm{RPFA}}^{k}=\sum_{i=1}^{n} A_{(\mathrm{RPFA}) i}^{k}+\sum_{i=1}^{n} a_{(\mathrm{RPFA}) i}^{k} \\
& S_{\mathrm{RNFA}}^{k}=\sum_{i=1}^{n} A_{(\mathrm{RNFA}) i}^{k}+\sum_{i=1}^{n} a_{(\mathrm{RNFA}) i}^{k}
\end{aligned}
$$


where $\mathrm{RPFA}^{k}, \mathrm{RNFA}^{k}$ and $\mathrm{RFA}^{k}$ respectively denote RPFA, RNFA, and RFA in $k$ sample plot. $A_{(\mathrm{RPFA}) i}^{k}$ and $A_{(\mathrm{RNFA}) i}^{k}$ respectively denote the area of the $i$ patch of abandoned paddy field and the abandoned non-irrigated farmland in $k$ sample plot. $a_{(\mathrm{RPFA}) i}^{k}$ and $a_{(\mathrm{RNFA}) i}^{k}$ respectively denote the area of patch $i$ of cultivated paddy and cultivated non-irrigated farmland in sample plot $k . S_{\mathrm{RPFA}}^{k}$ and $S_{\mathrm{RNFA}}^{k}$ denote the total area of paddy fields and non-irrigated farmland in sample plot k. $i$ denotes the number of patches $(i=1,2,3 \ldots n)$ and $k$ denotes the sampled plot $(1,2,3, \ldots 455)$.

Then, the frequency of RPFA, RNFA, and RFA in sample plots was calculated in IBM SPSS Statistics19. The results are given in Figure 2.

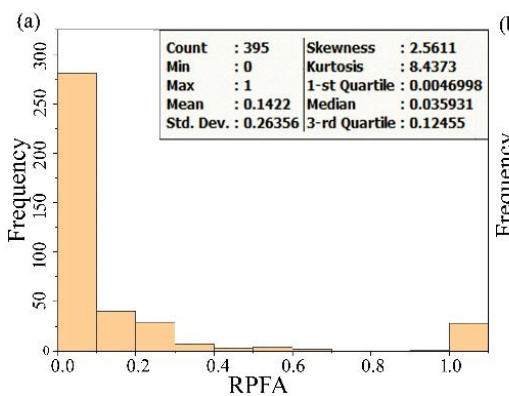

(a) Histogram of the rate of paddy field abandonment (RPFA)

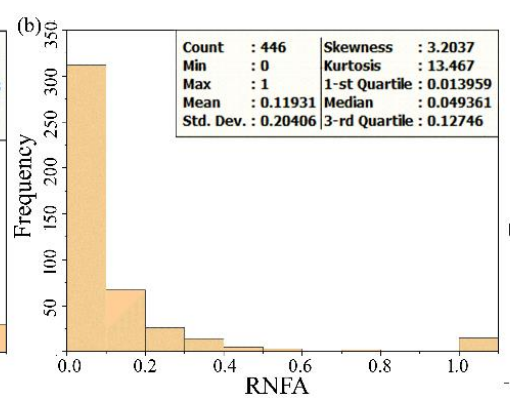

(b) Histogram of the rate of non-irrigated farmland abandonment (RNFA)

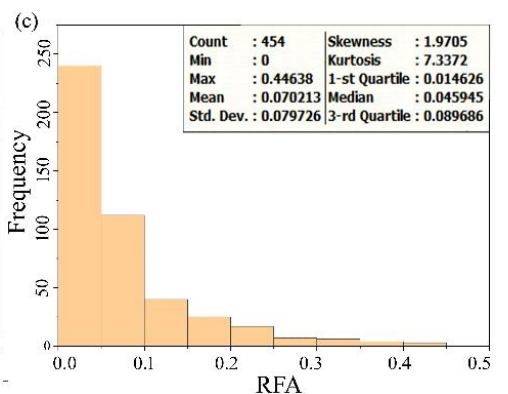

(c) Histogram of the rate of farmland abandonment (RFA)

Figure 2. Histogram of the rate of paddy field abandonment (RPFA), rate of non-irrigated farmland abandonment (RNFA), and rate of farmland abandonment (RFA).

\subsubsection{Identification of Abandonment Hot Spots}

The hot-spot analysis was realized by local spatial autocorrelation based on a distance-weight matrix. The Getis-Ord $\mathrm{Gi}^{*}$ Index $\left(G_{i}^{*}\right)$ was used to analyze the locations where center points of elements in the 455 sample plots with high or low values were spatially clustered. The computation formula of Getis-Ord $G i^{*}$ is as follows [34]:

$$
G_{i}^{*}=\frac{\sum_{j=1}^{n} w_{i, j} x_{j} \bar{X} \sum_{j=1}^{n} w_{i, j} x_{j}}{S \sqrt{\frac{n \sum_{j=1}^{n} w_{i, j}^{2}-\left(\sum_{j=1}^{n} w_{i, j}\right)^{2}}{n-1}}}
$$

where $x_{j}$ denotes the RPFA, RNFA, and RFA in $j$ sample plot, $w_{i, j}$ denotes the spatial weight between $i$ sample center point and $j$ sample center point, and $n$ denotes the number of center points of patches in the 455 sample plots.

$$
\begin{gathered}
\bar{X}=\frac{\sum_{j=1}^{n} w_{j}}{n} \\
s=\sqrt{\frac{\sum_{j=1}^{n} x_{j}^{2}}{n}-(\bar{x})^{2}}
\end{gathered}
$$

The significant and positive $G_{i}^{*}$ indicates that RPFA, RNFA, and RFA of sample plot $i$ and its surroundings is high, which means it belongs to the hot-spot area. If $G_{i}^{*}$ is significant and negative, it is indicated that the abandonment rate of $i$ sample plots and its surrounding area is low, which means it belongs to the cold-spot area. When $G_{i}^{*}$ is 0 , it indicates that there is no statistical significance, indicating that the random nature of the abandonment rate in sample plots $i$ and its surroundings is relatively large, which means it belongs to the abandonment random region. The optimization hot-spot analysis tool in Arcgis10.3 has been used for the clustering process. The hot- and cold spots 
are classified according to the value of $G_{i}^{*}$, expressed by probability Gi_Bin $\left(-3 \leq \mathrm{Gi} \_\right.$Bin $\left.\leq+3\right)$. The cold- and hot spots are classified as shown in Table 1.

Table 1. The confidence and criteria for cold-spot and hot-spot identification.

\begin{tabular}{ccc}
\hline Gi_Bin & Confidence & Cold-Hot Spot \\
\hline-3 & $99 \%$ & Cold spots \\
-2 & $95 \%$ & Cold spots \\
-1 & $90 \%$ & Cold spots \\
0 & No statistical significance & Random distribution point \\
1 & $90 \%$ & Hot spots \\
2 & $95 \%$ & Hot spots \\
3 & $99 \%$ & Hot spots \\
\hline
\end{tabular}

The optimized hot-spot analysis tool in ArcGIS10.3 was used to map cold- and hot spots showing the farmland abandonment rate in Sichuan Province.

\section{Results}

\subsection{Frequency of RPFA, RNFA, RFA of Sample Plots}

The RPFA, RNFA, and RFA of the sampled plots showed a skewed distribution, with obvious concentration on the left part of the histogram, as shown in Figure 2a-c.

The RPFA showed a skewed distribution, with obvious concentration on the left part of the histogram, with skewedness of 2.5611 and kurtosis of 8.4373, which exceeds the normal distribution value of 3 in Figure 2a. The mean RPFA was 0.1422. The RPFA in Sichuan Province has heterogeneity. There were neither patches of abandoned paddy field nor patches of cultivated paddy field in 60 sample plots. Of the 395 sample plots in which paddy fields appeared, 73 had no patches of abandoned paddy field; i.e., RPFA of the 73 sample plots equaled 0 . The RPFA of the 28 sample plots was 1 . The frequency of RPFA in the 395 sample plots in which paddy fields appeared is illustrated by Figure 2a.

The frequency of RNFA in the 446 sample plots is illustrated by Figure $2 \mathrm{~b}$. The RNFA of the 446 sampled plots had a skewed distribution, with a skewedness of 3.2037 and kurtosis of 13.467. The mean RNFA was 0.1193 . There were neither patches of abandoned non-irrigated farmland nor patches of cultivated non-irrigated farmland in 9 sample plots. Of 446 sample plots where non-irrigated farmland appeared, there were no patches of non-irrigated farmland abandoned in 42 plots; all patches of non-irrigated farmland were abandoned in 15 plots. Therefore, the RNFA was 0 in 42 sample plots, and equaled 1 in 15 sample plots.

RFA of the 454 sampled plots where farmland appeared showed a skewed distribution, with a skewedness of 1.9705 and kurtosis of 7.3372, which exceeds the normal distribution value of 3 in Figure 2c. The mean RFA was 0.0702 and the maximum RFA was 0.4464 . There were neither paddy fields nor non-irrigated farmland in 1 sample plot. There were no patches of abandoned farmland in 38 of 454 sample plots. The RFA of sample plots was 0 . The frequency of RFA in the 454 sample plots is illustrated by Figure 2c.

\subsection{Variation of RPFA, RNFA, and RFA among Landform Zones}

Farmland abandonment showed obvious variation among and within landform zones (Figures 3 and 4). The variation of the RPFA among the sample plots was the largest in Hilly Area in Basin, followed by that in Basin Periphery Mountain, West Basin Plain, and Western Sichuan Alpine Plateau, and the smallest was in Southwest Sichuan Mountain. The median value of the RPFA in Hilly Area in Basin was the highest, followed by that in Basin Periphery Mountain, West Basin Plain, and Western Sichuan Alpine Plateau, and the lowest was in Southwest Sichuan Mountain (Figure 4a). The difference in the RNFA among the sample plots was the largest in Hilly Area in Basin, followed by that in the West Basin Plain, Basin Periphery Mountain, and Western Sichuan Alpine Plateau, and was 
the smallest in Southwest Sichuan Mountain. The median value of the RPFA was the largest in Hilly Area in Basin, followed by that in the Basin Periphery Mountain, Western Sichuan Alpine Plateau, and West Basin Plain, and was the lowest in Southwest Sichuan Mountain (Figure 4b). Among the landform zones, the Hilly Area in Basin had the largest difference of RFA among the sample plots, followed by that in the Basin Periphery Mountain, Western Sichuan Alpine Plateau, West Basin Plain, and Southwest Sichuan Mountain. The median value of the RFA in Hilly Area in Basin was the highest, followed by that in the Basin Periphery Mountain, Western Sichuan Alpine Plateau, and West Basin Plain, and was the lowest in Southwest Sichuan Mountain (Figure 4c).

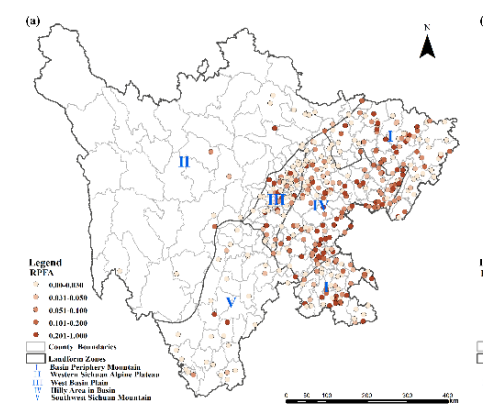

(a) Spatial distribution of the RPFA of sample plots in Sichuan Province

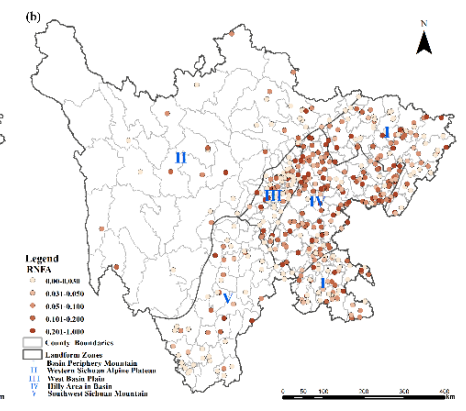

(b) Spatial distribution of the RNFA of sample plots in Sichuan Province

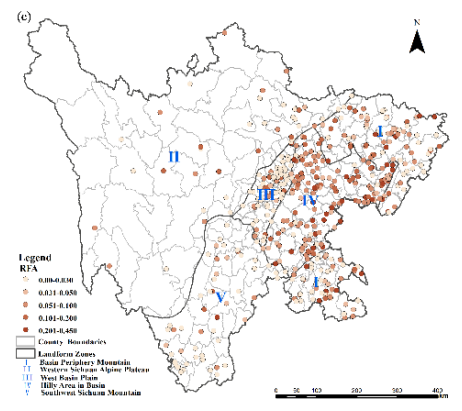

(c) Spatial distribution of the RFA of sample plots in Sichuan Province

Figure 3. Spatial distribution of the RPFA, RNFA, and RFA of sample plots in Sichuan Province.

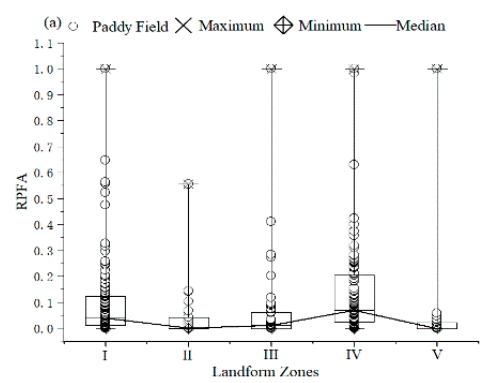

(a) Statistical distribution of RPFA among landform zones

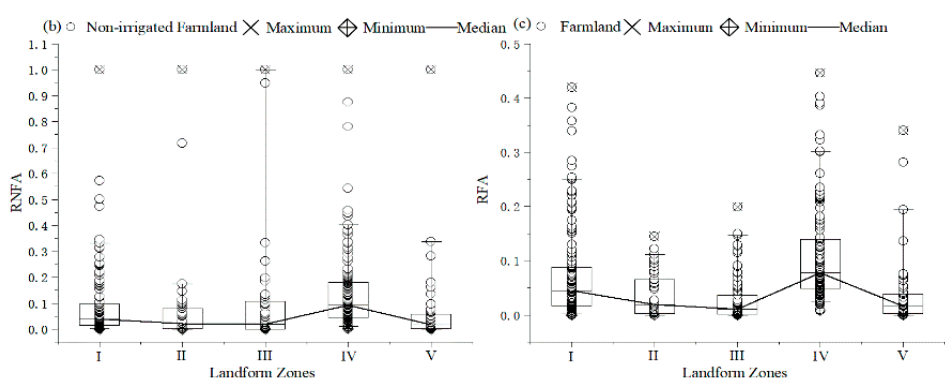

(b) Statistical distribution of

(c) Statistical distribution of RNFA among landform zones
RFA among landform zones

Figure 4. Statistical distribution of RPFA, RNFA, and RFA among landform zones.

\subsection{Cold- and Hot Spots of Farmland Abandonment}

The Getis-Ord $\mathrm{G}_{\mathrm{i}}^{*}$ index value of the sample plots was calculated using Formulas (7)-(9). The Gi_Bin interval was used to determine the spatial aggregation characteristics of cold- and hot spots. The optimized hot-spot analysis tool in ArcMap10.3 was used to make Figure 5a-c according to Table 1. There is obvious spatial variation in cold- and hot spots of the RPFA (Figure 5a), RNFA (Figure 5b), and RFA (Figure 5c) in Sichuan Province.

There was no clustering of Gi_Bin values of $-3,-2,-1$, and 1 in the spatial cold- and hot-spot analysis of RPFA in Figure 5a. The following regions had Gi_Bin values of 2 and 3: Anyue, Zizhong, Dongxing, Da'an, Fushun, and Longchang in Hilly Area in Basin; and Xichang and Puge in Western Sichuan Alpine Plateau; with a cluster statistical significance of $99 \%$, and these will be hot-spot areas of paddy field abandonment in the future. Gi_Bin of the other counties was 0, with no statistical significance in spatial clustering, where paddy field abandonment is random. 
There was no clustering of Gi_Bin of $-3,-2,-1,2,3$ in the spatial cold- and hot-spot analysis of the RNFA (Figure 5). Gi_Bin of the following regions was 1: Xiaojin and Baoxing in Western Sichuan Alpine Plateau; Anzhou, Youxian, Yanting, and Santai in Hilly Area in Basin; with cluster statistical significance of $90 \%$ confidence, and these will be hot-spot areas of non-irrigated farmland abandonment in the future. Like the rate of paddy field abandonment, the Gi_Bin values of the other counties were 0 , with no statistical significance in spatial clustering, and the non-irrigated farmland abandonment was random.

The cold- and hot spots of the RFA in Sichuan Province are shown in Figure 5. The clustering characteristics of spatial cold- and hot spots of the RFA are obvious, including all regions with Gi_Bin of $-3,-2,-1,0,1,2$ and 3. More than 30 counties in Hilly Area in Basin, and Huaying and Linshui in Basin Periphery Mountain, had Gi_Bin of 1, 2, 3, and with a confidence score of 90\%, 95\%, and 99\%, which implies a clustering with statistical significance. These regions will be hot-spot areas of farmland abandonment in the future. Eighteen counties in West Basin Plain and 20 counties in Southwest Sichuan Mountain are cold-spot areas of RFA, with Gi_Bin of -1,-2,-3. Gi_Bin of the other counties was 0 , with no statistical significance in spatial clustering, where the farmland abandonment was random.

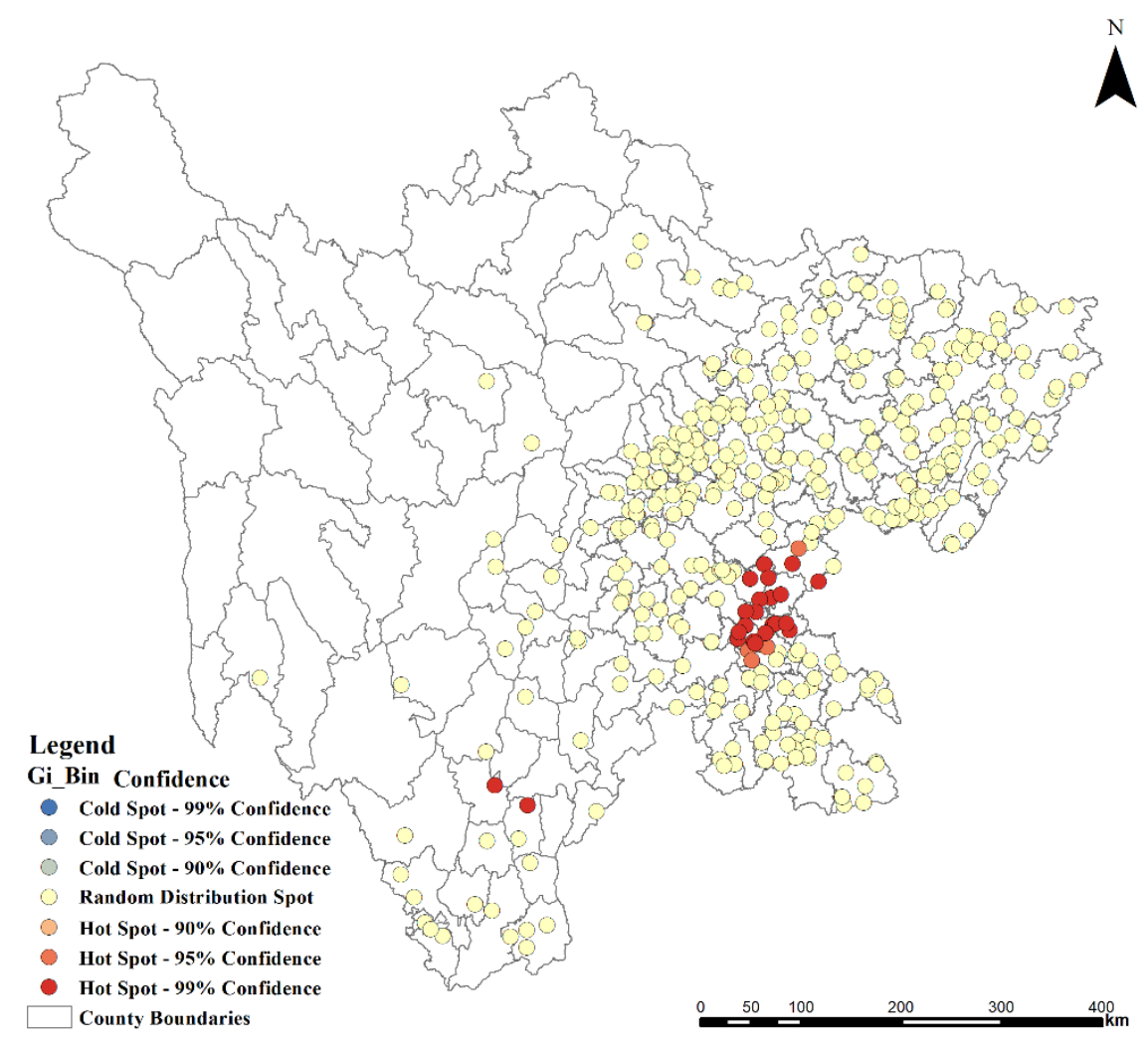

(a)

Figure 5. Cont. 


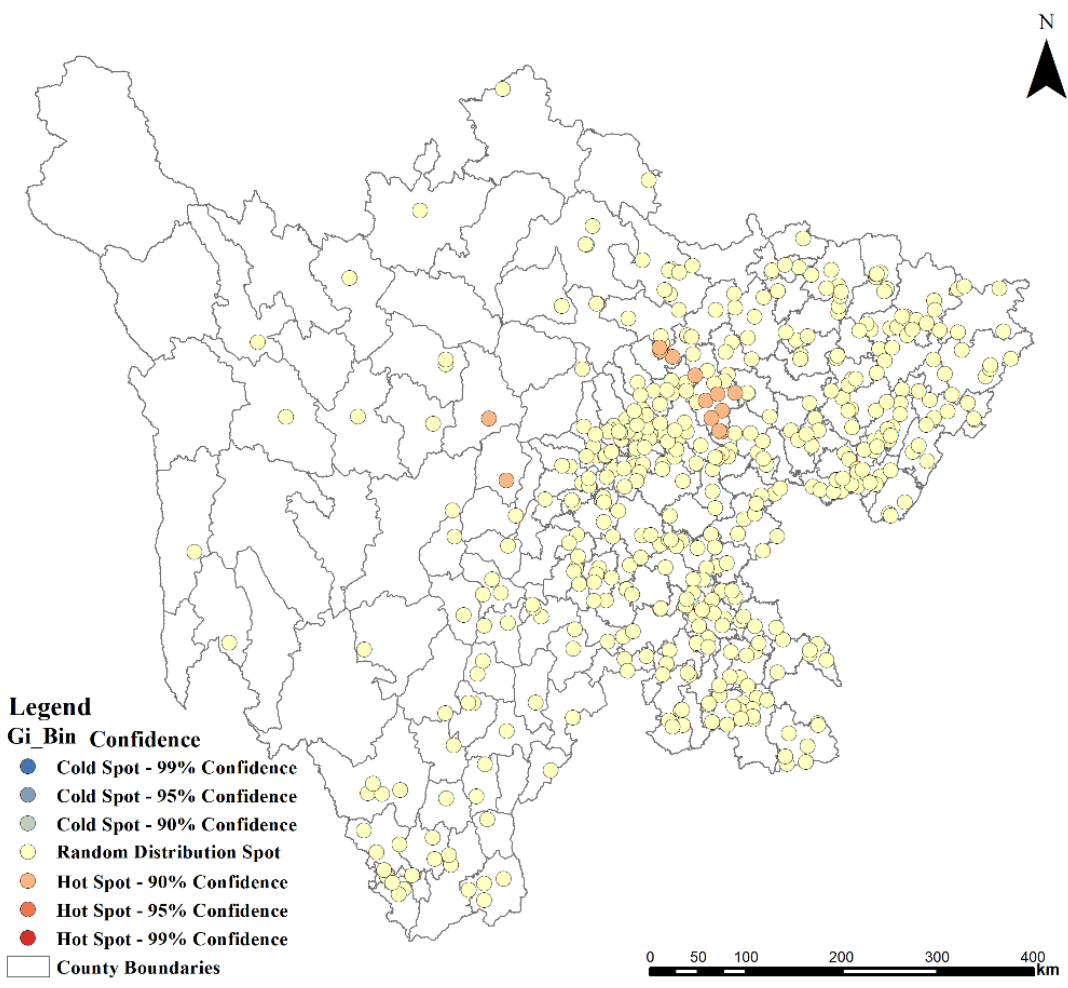

(b)

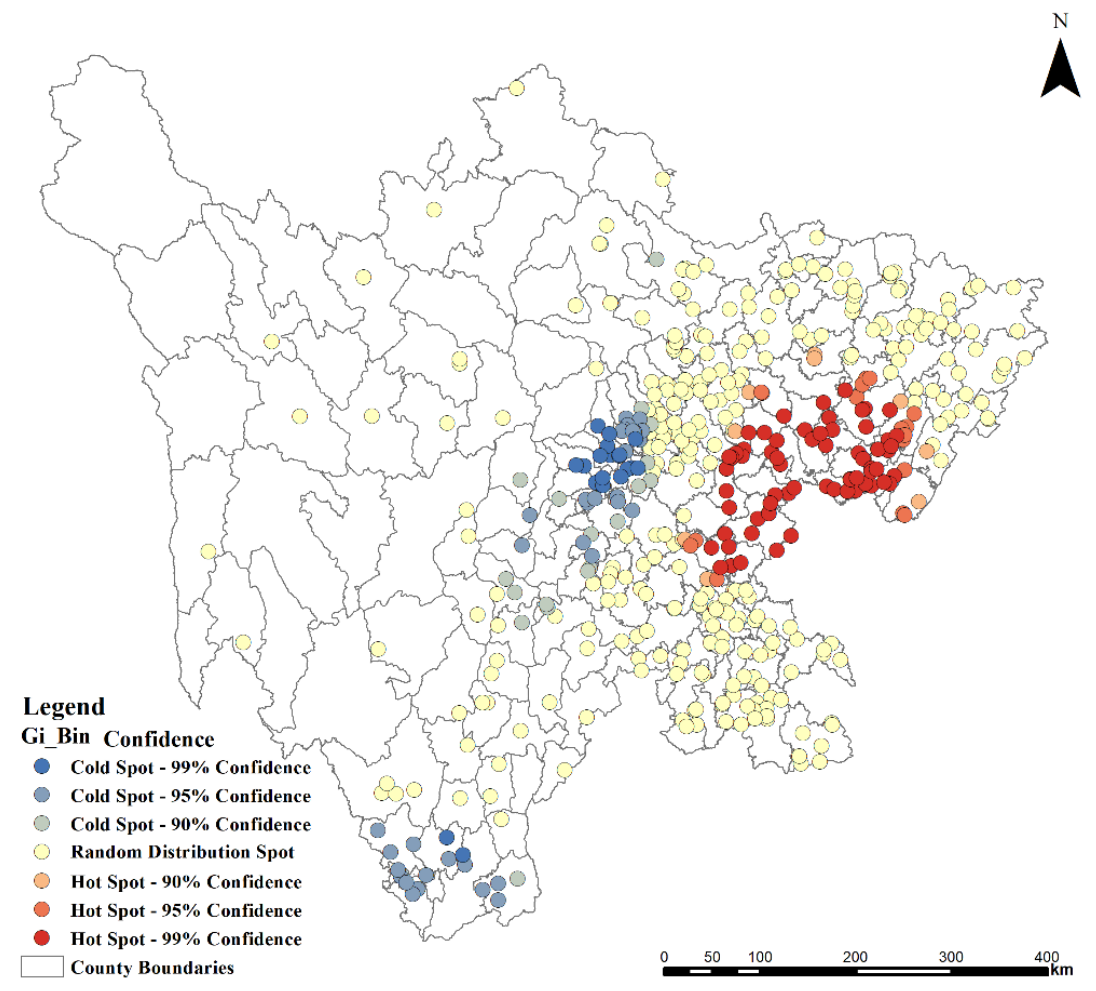

(c)

Figure 5. (a) Spatial pattern of cold- and hot spots of the RPFA in sample plots in Sichuan Province. (b) Spatial pattern of cold- and hot spots of the RNFA in sample plots in Sichuan Province. (c) Spatial pattern of cold- and hot spots of the RFA in sample plots in Sichuan Province. 


\section{Discussion}

The distribution of farmland in Sichuan Province is highly varied due to various reasons. The proportion of farmland is low in the Western Sichuan Alpine Plateau, where the main income of farmers is sourced from grazing and picking Chinese caterpillar fungus. The rural residential district in the Western Sichuan Alpine Plateau is distributed on the terraces along rivers. The distance of farms to residential parcels affects not only the spatial pattern of rural residential districts $[35,36]$, but also the degree of farmland aggregation [37]. Farmland is mainly located around the rural residential areas in Sichuan Province. The 455 sample plots surveyed in this study, each covering $1 \mathrm{~km}^{2}$, are mainly concentrated in the West Basin Plain (73 sample plots), Hilly Area in Basin (148 sample plots), and Basin Periphery Mountain (141 sample plots), which are the primary grain-producing areas in Sichuan Province. Of the 455 sample plots, 52 plots are located in the South West Sichuan Mountain, and 41 are located in the Western Sichuan Alpine Plateau, which has limited land resources and is sparsely populated [32]. The abandonment rates of paddy field (RPFA) and non-irrigated farmland (RNFA) have 0 and 1 , suggesting that they are convergent. The rate of farmland abandonment (RFA) has no void value and 1 . The reason is that agriculture is affected by climate, water, soil, heat, light, and other factors [38]. Sichuan Province is a very large area and is divided into five landform zones. There were no paddy fields in some sample plots, and there was no non-irrigated farmland in some other sample plots. RFA would well express the overall level of farmland abandonment in the Sichuan Province.

The spatial heterogeneity of farmland abandonment in Sichuan Province is significantly influenced by regional geomorphological and agricultural conditions, such as elevation, relative relief, aspect, slope, climate, water, soil, heat, light, farmland resource endowments, rural labor allocation $[2,4,6]$, and rural economic development $[9,10]$.

The RPFA, RNFA, and RFA of sample plots in Southwest Sichuan Mountain with good light and heat are lower than those of other areas, because farmland abandonment is affected by the climate of the area. Light and heat affect the growth of crops, and the production of the plots with good light and heat was higher than the plots with poor light and heat. The RPFA, RNFA, and RFA of Panzhihua City, which is located in Southwest Sichuan Mountain Area, were comparatively low, because the area has sufficient sunshine; specifically a total quantity of annual radiation of 5600-6300 MJ $/ \mathrm{m}^{2}$ [39]. Most farmland has been replanted with fruits that like light and heat, such as mangos, loquats, pomegranates, lotuses, strawberries, and cherries in Panzhihua City.

The RPFA, RNFA, and RFA of sample plots in West Basin Plain with a flat terrain were lower than those in both Western Sichuan Alpine Plateau and Basin Periphery Mountain, as flat land is easier to cultivate with machines. Further, urbanization plays a critical role in farmland abandonment. The Chengdu megalopolis has a great population, along with a sprawl of urbanized areas; as a result a large number of high-quality patches of farmland have been converted into built-up areas [40], and the per capita farmland area is gradually decreasing. Meanwhile, a large number of farmland plots have been converted into orchards that produce high yields and economic benefits in West Basin Plain.

Economic development plays an important role in the farmland abandonment. The RPFA, RNFA, and RFA are lower in both Basin Periphery Mountain Area and Western Sichuan Alpine Plateau than Hilly Area in Basin. One reason is that the economic development level in those areas is lower than that in Hilly Area in Basin. Both total and per capita amounts of GDP are lower than the provincial average [41]. The impact of abandonment on family income is greater than in other areas. Most people in these areas prefer to cultivate their farmland to gain family income. The other reason is that farmland and rural residential districts in mountainous areas are distributed across flatter terrain, and cultivation is easier in the mountains than in hilly areas [42].

However, spatial heterogeneity of the farmland abandonment in Sichuan Province is the result of various forces. For instance, the RPFA, RNFA, and RFA in Hilly Area in Basin are higher than in other areas. There are many reasons for this including: (1) fragmentation of farmland plots that limit application of agricultural mechanization [43]; (2) large agricultural populations with low education levels; (3) high loss of labor forces from rural areas to urban areas [44], and aged farmers, with some 
more than 64 years old [45]; (4) the weather in Hilly Area in Basin, which is often cloudy, and the sunlight is reflected by cloud and mist. The areas have poor light and heat, which is not good for cultivating high-quality fruits and grains.

In line with other studies, we found there is heterogeneity in the spatial distribution of regional farmland abandonment [21] in Sichuan Province. Ding (2019) found that the regions with relatively large cropland abandonment rates and size are mainly distributed in the west and south of China (e.g., Sichuan Province, Chongqing Municipality), while the rate of cropland abandonment in the north and northeast area of China is relatively low [46]. Farmland abandonment in Japan exhibits a significantly uneven pattern. Most abandoned farmland is positively correlated with slope and is highly clustered in the Kanto, $\mathrm{Chubu}$, and Chugoku Shikoku regions, compared to other regions that are suitable for agricultural production, such as the Hokkaido and Tohoku regions [47]. Townships have widely different abandonment rates in Chongqing [21]. Farmland abandonment is significantly more common in mountainous areas than in plains areas [1]. Farmland abandonment is also more prone to occur on patches that are remote from the laborers' residences [22,48].

In our study, the average RFA of sample plots in Sichuan Province was less than 0.2. It is lower than that of other studies. The RFA reached 0.29 in Wushan, Chongqing [49], the values were 0.37 and 0.25 in Gansu Province and Tianjin [1] respectively, while an estimation of the national RFA in mountainous counties of China reached 0.28 [50], and the average RFA was 0.29 in Three Gorges Reservoir Area [22]. There might be four reasons for this difference. Firstly, actual abandoned patches of farmland were excluded from the investigation, which could result in a significant underestimation of the abandoned farmland. Secondly, patches of farmland had been abandoned for more than three years, and became like thickets of forestland in our investigation, which would give rise to a lower RFA. Thirdly, the abandoned farmland was mainly distributed in areas with a distance of more than $500 \mathrm{~m}$ from villages [22]; the 455 random sample plots were near the residential districts, which would give a lower RFA than for the other areas. Fourthly, the assessment of other studies was based on MODIS data, low-resolution remote sensing data, and questionnaires, which would give a higher RFA than methods used in this study.

Since Sichuan is vital in China for its agriculture, the results of this study have very important implications. A number of regions with relatively large cropland abandonment rates are located in the Sichuan Province of China [46]. The authors' findings may prove to be useful in order to identify the main areas of future farmland abandonment, which can provide ideas about study on the mechanisms and factors of abandoned farmland in different regions in the future.

\section{Conclusions}

In this study, the heterogeneity of farmland abandonment in Sichuan Province is focused on. Patches of abandoned paddy fields, abandoned non-irrigated farmland, cultivated paddy fields, and cultivated non-irrigated farmland were investigated using $4551 \mathrm{~km}$-by- $1 \mathrm{~km}$ sample plots in Sichuan Province. The rate of paddy field abandonment (RPFA), the rate of non-irrigated farmland abandonment (RNFA), and the rate of farmland abandonment (RFA) of sample plots were calculated in this study, and are confirmed suitable indicators for revealing the spatial heterogeneity of farmland abandonment in Sichuan Province. The proportion of paddy fields and non-irrigated farmland is different among landform zones of Sichuan Province. This was the first attempt to divide the abandoned farmland into abandoned paddy fields and abandoned non-irrigated farmland in a study of Sichuan Province.

Farmland abandonment in the province showed great spatial heterogeneity. Variation of RPFA and RNFA among the sample plots differed among landform zones. The rate of paddy field abandonment (RPFA), the rate of non-irrigated farmland abandonment (RNFA), and the rate of farmland abandonment (RFA) in the Hilly Area in Basin were high, but low in West Basin Plain and South West Sichuan Mountainous Area, and intermediate in the Western Sichuan Alpine Plateau and the Basin Periphery Mountain Area. RPFA, RNFA, and RFA of sample plots showed a high narrow peak and positive 
skewed distribution (F distribution). The rate of farmland abandonment (RFA) well expresses the overall level of farmland abandonment in Sichuan Province.

The hot-spot areas of paddy field abandonment were mainly concentrated in the area where the main stream of the Yangtze River flows through the Hilly Area in Basin, which is also the area where paddy fields are concentrated. There was not a cold-spot area of paddy field abandonment in Sichuan Province. There were 10 sample plots in hot-spot areas of non-irrigated farmland abandonment located in the north of Hilly Area in Basin, which will be hot-spot areas for non-irrigated farmland abandonment in the future. The clustering characteristics of spatial cold- and hot spots of the rate of farmland abandonment (RFA) are obvious. The hot-spot areas of RFA are in Hilly Area in Basin, while the cold-spot areas of RFA are in West Basin Plain and the south of Southwest Sichuan Mountain areas, and farmland abandonment is random in the other areas.

Author Contributions: Conceptualization, Y.W. and Q.L.; data curation, W.T.; formal analysis, Y.W.; funding acquisition, Y.W. and Q.L.; methodology, Z.C.; project administration, P.P. and Y.W.; supervision, P.P. and Y.W.; Writing-Original Draft, Y.W.; Writing-Review and Editing, P.P. and Q.L. All authors have read and agreed to the published version of the manuscript.

Funding: This research was funded by the National Social Science Fund of China (No: 19xjy008), the Basic research business fee provided by the China West Normal University (No. 17c033).

Acknowledgments: More than 500 students from the School of Land and Resources at China West Normal University contributed to the collection of survey data and to the construction of a database. We would like to express our sincere give our thanks to all of these students.

Conflicts of Interest: The authors declare no conflict of interest.

\section{References}

1. Li, S.F.; Li, X.B. Global understanding of farmland abandonment: A review and prospects. J. Geogr. Sci. 2017, 27, 1123-1150. [CrossRef]

2. Melendez, P.I.; Hernández, E.I.; Navarro-Pedreño, J. Socioeconomic factors influencing land cover changes in rural areas: The case of the Sierra de Albarracín (Spain). Appl. Geogr. 2014, 52, 34-45. [CrossRef]

3. Shi, T.C.; Xu, X.H. Extraction and validation of abandoned farmland parcels in typical counties of Chongqing. Trans. Chin. Soc. Agric. Eng. 2016, 32, 261-267. [CrossRef]

4. Andre, M.F. Depopulation, land-use change and landscape transformation in the French Massif Central. Ambio 1998, 27, 351-353. [CrossRef]

5. Gellrich, M.; Baur, P.; Koch, B. Agricultural land abandonment and natural forest re-growth in the Swiss mountains: A spatially explicit economic analysis. Agric. Ecosyst. Environ. 2007, 118, 93-108. [CrossRef]

6. Zhang, Y.; Li, X.B.; Song, W.; Shi, T.C. Effects of agricultural laborers on cropland abandonment under land circulation at different levels in Wulong County, Chongqing City. Prog. Geogr. 2014, 33, 552-560. [CrossRef]

7. Mottet, A. Agricultural land-use change and its drivers in mountain landscapes: A case study in the Pyrenees. Agric. Ecosyst. Environ. 2006, 114, 296-310. [CrossRef]

8. Kuki, Y.; Takahashi, T. A case study of practical uses of abandoned farmlands. J. Rural Plan. Assoc. 1999, 38, 247-252. [CrossRef]

9. Tian, Y.J.; Li, X.B.; Xin, L.J. Impacts of the rise of labor opportunity costs on agricultural land use changes. J. Nat. Resour. 2009, 24, 369-377. [CrossRef]

10. Ge, L.; Gao, M.; Hu, Z.F. Reasons for the abandonment of cultivated land in mountainous areas according to farmers' perspectives. Chin. J. Agric. Resour. Reg. Plan. 2012, 33, 42-46.

11. MacDonald, D.; Crabtree, J.; Wiesinger, G.; Dax, T.; Stamou, N.; Fleury, P.; Lazpita, J.G.; Gibon, A. Agricultural abandonment in mountain areas of Europe: Environmental consequences and policy response. J. Environ. Manag. 2000, 59, 47-69. [CrossRef]

12. Yamada, S.; Okubo, S.; Kitagawa, Y. Restoration of weed communities in abandoned rice paddy fields in the Tama Hills. Central Japan. Agric. Ecosyst. Environ. 2007, 119, 88-102. [CrossRef]

13. Matthias, B.; Tobias, K.; Marine, E.; Mutlu, O.; Volker, C.; Radeloff, N.S.; Keuler, A.V.; Prishchepov, I.K.; Patrick, H. Patterns and drivers of post-socialist farmland abandonment in Western Ukraine. Land Use Policy 2011, 28, 552-562. [CrossRef] 
14. Li, S.F.; Li, X.B.; Xin, L.J. Extent and distribution of cropland abandonment in Chinese mountainous areas. Resour. Sci. 2017, 39, 1801-1811. [CrossRef]

15. Duan, Y.M.; Zhou, H.; Liu, X.H. Research progress and prospects of farmland abandonment in China. Jiang Su Agric. Sci. 2018, 46, 13-17. [CrossRef]

16. Zhang, X.Z.; Zhao, C.S.; Dong, J.W. Spatiotemporal patterns of cropland abandonment in China from 1992 to 2017: A meta-analysis. Acta Geogr. Sin. 2019, 74, 411-420. [CrossRef]

17. Kolecka, N.; Kozak, J.; Kaim, D.; Dobosz, M.; Ostafin, K.; Ostapowicz, K.; Wezyk, P.; Price, B. Understanding farmland abandonment in the Polish Carpathians. Appl. Geogr. 2017, 88. [CrossRef]

18. Stephan, E.; Tobias, K.; Camilo, A.; Christian, L.; Patrick, H. Mapping farmland abandonment and recultivation across Europe using MODIS NDVI time series. Remote Sens. Environ. 2015, 7, 312-325. [CrossRef]

19. Jean, M.T.; Luigi, N.S.; Annett, W.; Margarida, A.; Aija, Z. Farmland abandonment in Europe: Identification of drivers and indicators, and development of a composite indicator of risk. Land Use Policy 2015, 49, $20-34$. [CrossRef]

20. Jin, F.F.; Xin, L.J. Spatial distribution and impact factors of farmland abandonment. Resour. Sci. 2018, 40, 719-728. [CrossRef]

21. Tie, C.S.; Xiu, B.L.; Liang, J.X.; Xiao, H.X. The spatial distribution of farmland abandonment and its influential factors at the township level: A case study in the mountainous area of China. Land Use Policy 2018, 510-520. [CrossRef]

22. Chen, Y.F.; Wang, Y.K.; Fu, B.; Wang, H. Spatial patterns of farmland abandonment and its impact factors in the central Three Gorges Reservoir Area. J. Mt. Sci. 2018, 15, 631-644. [CrossRef]

23. Wang, L.; Li, X.X. "Abandoned farmlands" image features analysis and information extraction-In case of Niu xinbao township in You yu. J. Liaoning Norm. Univ. (Nat. Sci. Ed.) 2017, 40, 519-524.

24. Camilo, A.; Tobias, K.; Matthias, B.; Eugenia, V.B.; Patrick, G.; Patrick, H.; Jan, K.; Daniel, M.; Alexander, V.P.; Florian, S.; et al. Mapping the extent of abandoned farmland in Central and Eastern Europe using MODIS time series satellite data. Environ. Res. Lett. 2013, 8. [CrossRef]

25. Li, Y.T.; Liu, J.B.; Wang, Z.W. Study on spatiotemporal dynamic change and climate response of snow cover in Sichuan Province from 2003 to 2012. Glac. Permafr. 2016, 38, 1491-1500.

26. Ning, K.; Wang, S.Y. A study of geomorphological regionalization of Sichuan using GIS and RS. Yunnan Geogr. Environ. Res. 2018, 30, 47-54. [CrossRef]

27. Dong, C.W.; Rui, X.P.; Deng, Y. Study on dimension reduction of spatial economic statistics: A case study of economic statistical data of Sichuan. Geogr. Res. 2012, 31, 1411-1421.

28. Xiao, H.; Sun, X.F.; Wu, K.J. Land use information extraction in typical landform regions of Sichuan Province. Geosp. Inf. 2016, 14, 81-83. [CrossRef]

29. Luo, X.; Hua, G.C. Characteristics of soil and water loss in power transmission and transformation construction and monitoring of soil and water conservation. Anhui Agric. Sci. 2015, 43, 182-198. [CrossRef]

30. Zeng, Y.M.; Zhang, G. Study on county-level economic spatial disparity based on GEO-GIS in Sichuan Province. Yunnan Geogr. Environ. Res. 2010, 22, 52-58. [CrossRef]

31. Statistical Bureau of Sichuan. Statistical Communique of National Economic and Social Development of Sichuan Province in 2018. Sichuan Daily 11, 6 March 2019.

32. Wojciech, S.; Bernd, P.; Tomasz, W.; Miroslaw, S.; Paulina, S.; Olga, P. Determinants of Farmland Abandonment in Selected Metropolitan Areas of Poland: A Spatial Analysis on the Basis of Regression Trees and Interviews with Experts. Sustainability 2019, 11, 3071. [CrossRef]

33. Wu, Z.H.; Feng, Y.Q.; Mu, J.Y. Analysis on the bearing capacity of cultivated land in Sichuan Province. Sci. Technol. Sichuan Agric. 2004, 3, 4-5. [CrossRef]

34. Getis, A.; Ord, J.K. The analysis of spatial association by use of distance statistics. Geogr. Anal. 1992, 24, 189-206. [CrossRef]

35. Diao, C.T. The features and evolution of the pattern of landforms in Sichuan-Some insights on compiling the 1:1000000 geomorphological map of Sichuan Province. J. Southwest China Teach. Univ. (Nat. Sci.) 1991, 3, 384-388. [CrossRef]

36. Zhao, Y.; Hu, Y.M.; Zhang, X.C. Spatial pattern of farming distance in rural area using ESDA. Sci. Geogr. Sin. 2016, 36, 760-765. [CrossRef] 
37. Xie, Z.; Zhang, F.R.; Gao, Y. Comparison on evolution of rural farmland use in poverty-stricken counties between flat and mountainous areas based on remote sensing and GIS. Trans. Chin. Soc. Agric. Eng. 2018, 34, 255-263. [CrossRef]

38. Sun, Y.F. Geomorphological conditions for developing agricultural production in Southern Anhu. J. Anhui Norm. Univ. (Nat. Sci. Ed.) 1978, Z1, 102-108. [CrossRef]

39. Feng, S.J.; Li, S.M. Analysis of building application potential of solar energy resources in Pan Zhihua area. Sichuan Arch. 2016, 36, 84-88. [CrossRef]

40. Zhang, Z.L.; Jia, Y.Y. Spatial and temporal evolution of cultivated land pressure in the Chengdu Plain Economic Zone. Rural Econ. Sci. Technol. 2018, 29, 10-12. [CrossRef]

41. Jin, X.Q. Study of the path of county economic development in Sichuan's mountainous areas under the new normal. Contemp. Cty. Econ. 2016, 11, 34-36. [CrossRef]

42. Zhong, K.Q.; Li, A.D.; Wu, W. The influence of terrain factors on the distribution of rural scattered settlements in the mountainous areas of Southwest China. Hunan Agric. Sci. 2017, 2, 107-113. [CrossRef]

43. Xu, H.X.; Xue, W.R.; Peng, W.F. Analysis of influencing factors of agricultural economic growth in the middle hilly areas of Sichuan Province. Resour. Dev. Mark. 2015, 31, 537-539. [CrossRef]

44. Wang, J.; Zhang, T.; Wei, S. Causes and countermeasures of rural hollowing in hilly areas of Sichuan. Contemp. Econ. 2017, 22, 90-91.

45. Ding, D.X.; Shi, J.G.; Fang, T.X. The impact of rural laborer migration and household structure on household land use arrangements in mountainous areas of Sichuan Province, China. Habitat Int. 2017, 70, 72-80. [CrossRef]

46. Ding, D.X.; Xin, D.; Kai, H.; Yi, L.; Zhuo, L.Y.; Shao, Q.L. Relationships between labor migration and cropland abandonment in rural China from the perspective of village types. Land Use Policy 2019, 88, 104164. [CrossRef]

47. Guan, D.S.; Hidenori, O.S.; Lin, C. Spatial Pattern of Farmland Abandonment in Japan: Identification and Determinants. Sustainability 2018, 10, 3676. [CrossRef]

48. Ying, Z.; Xiu, B.L.; Wei, S. Determinants of cropland abandonment at the parcel, household and village levels in mountain areas of China: A multi-level analysis. Land Use Policy 2014, 41, 186-192. [CrossRef]

49. Yu, C.G.; Wei, S. Spatial Distribution and Simulation of Cropland abandonment in Wushan County, Chongqing, China. Sustainability 2019, 11, 1367. [CrossRef]

50. Li, S.; Li, X.; Sun, L.; Cao, G.; Fischer, G.; Tramberend, S. An estimation of the extent of cropland abandonment in mountainous regions of China. Land Degrad. Dev. 2018, 29, 1327-1342. [CrossRef] 